\title{
When is there not enough salt for ants?
}

\author{
M. Breed ${ }^{1}$
}

Published online: 10 April 2015

(C) International Union for the Study of Social Insects (IUSSI) 2015

Getting enough sodium can pose real nutritional challenges for animals in terrestrial habitats. Water-soluble mineral nutrients like sodium often exist as rare commodities. Precipitation washes these nutrients downstream, leaches them from soils, and dilutes them in bodies of water. The availability of simple minerals like sodium limits communities of plants and animals that live on geologically older soils with long histories of nutrient washing and leaching. This is exacerbated in ecosystems in which micronutrient input from sources like dust and volcanic ash is limited.

Sodium is likely more limiting for herbivore than for omnivores or carnivores. Herbivores cannot obtain much sodium from their plant diets. Animals that eat animal tissues usually have ample sodium in their diet. Thus, the effects of nutrient scarcity do not play out the same at all trophic levels.

In this issue of Insectes Sociaux, Vieira and Vasconcelos (2015) report a revealing study of ant responses to sodium baits in the Cerrado habitat of central Brazil. This dry ecosystem houses extraordinarily species-rich mixed forest and savanna communities (Simon et al. 2009). The Cerrado supports a highly diverse ant assemblage and previous studies had suggested that mineral limitation might affect animals in this ecosystem. Vieira and Vasconcelos (2015) surveyed ant communities for responses to sodium baits in Cerrado grasslands and trees following methods established by Kaspari et al. (2008). The assay includes tests of responsiveness to differing concentrations of sodium and

M. Breed

michael.breed@colorado.edu

1 Department of Ecology and Evolutionary Biology, University of Colorado, Boulder, CO 80309-0334, USA also for their responsiveness to sucrose. Preferential attraction to sodium over sucrose suggests that a species or population is limited by sodium availability.

Vieira and Vasconcelos (2015) found in part the expected, that ants occupying lower trophic positions were more attracted to salt baits. Unexpectedly, they found that arboreal ants were more likely to have a high preference for sodium than were ground-dwelling ants. This suggests that sodium is a more limiting nutrient for arboreal ants in this ecosystem. A phylogenetic analysis showed that sodium preference is widely distributed across ant taxa, supporting an argument for evolutionary convergence of ants to trophic status.

The importance of this study lies in its support for the hypothesis that tests for sodium responsiveness have general applicability in assessment of ant communities. The use of phylogenetic methods to assess community interactions gives a comprehensive dimension to the work. As would be expected from the findings of Kaspari et al. (2008), this study supports the utility of sodium preference assays in studies of trophic structure and nutrient limitation in ant assemblages.

The trophic diversity of ants makes them an interesting target of studies of nutritional limitations. As this work demonstrates, effects of scarcity can be assessed in a context in which evolution has created a replicated natural experiment by placing ants from different subfamilies into the same trophic context.

\section{References}

Kaspari M, Yanoviak SP, Dudley R (2008) On the biogeography of salt limitation: a study of ant communities. Proc Natl Acad Sci USA 105:17848-17851 
Simon MF, Grether R, de Queiroz LP, Skema C, Pennington RT, Hughes CE (2009) Recent assembly of the Cerrado, a neotropical plant diversity hotspot, by in situ evolution of adaptations to fire. Proc Natl Acad Sci USA 106:20359-20364
Vieira J, Vasconcelos HL (2015) Inter-generic and inter-habitat variation in the demand for sodium by Neotropical ants. Insect Soc 62:133-140. doi:10.1007/s00040-014-0382-2 